\title{
METODOLOGIAS ATIVAS E RECURSOS DIGITAIS PARA O ENSINO DE L2: UMA REVISÃO SOBRE CAMINHOS E POSSIBILIDADES
}

\author{
Rafael Vetromille-Castro ${ }^{1 *}$
}

Helena dos Santos Kieling ${ }^{1 * x}$

${ }^{1}$ Universidade Federal de Pelotas, Pelotas, RS, Brasil

\begin{abstract}
Resumo
O artigo é uma revisão sobre o tema das Metodologias Ativas e do Ensino Híbrido para o ensino de L2 integrado com tecnologias digitais, sobretudo como as Metodologias Ativas subsidiam duas lacunas frequentes na formação do docente de línguas: o ensino de L2 para crianças e a utilização integrada de recursos digitais. A primeira consiste na falta de abordagem para o ensino de L2 para crianças, de forma que sua prática pedagógica é uma bricolagem de elementos. A segunda enfatiza o uso de recursos digitais de forma integrada aos espaços de aprendizagem. É apresentada uma retomada dos conceitos de Metodologias Ativas e trazida a reflexão decorrente da temática para a formação docente hoje. O trabalho aponta a urgência desses temas nos cursos de licenciatura, bem como uma integração refletida de recursos digitais na prática pedagógica.

Palavras-chave: Metodologias Ativas; Ensino de L2 para crianças; Recursos Digitais; Formação de Professores
\end{abstract}

\footnotetext{
Graduado em Letras pela Universidade Federal de Pelotas (1998), Mestre em Linguística Aplicada pelo Programa de Pós-Graduação em Letras da Universidade Católica de Pelotas (2003) e Doutor em Informática na Educação pela Universidade Federal do Rio Grande do Sul (2007), atualmente é professor do Programa de Pós-Graduação em Letras stricto sensu e professor associado na área de língua inglesa do Centro de Letras e Comunicação da Universidade Federal de Pelotas (UFPel). Atua na área de Linguística Aplicada, tendo especial interesse de pesquisa na Aprendizagem de Línguas Mediada por Computador (CALL), no desenvolvimento linguístico e nas Teorias da Complexidade e do Caos. E-mail: vetromillecastro@gmail.com ORCID: https:// orcid.org/0000-0003-3672-2390

** Graduada em Licenciatura em Letras Português e Inglês. Desde a graduação trabalha com ensino de Língua Inglesa. Atuou como docente e Orientadora Pedagógica no Yázigi em Pelotas de 2007 a 2017. Em 2017, concluiu o Mestrado em Letras/Linguística Aplicada pelo Programa de Pós-Graduação em Letras da Universidade Católica de Pelotas com pesquisa sobre Blended Learning no ensino de Inglês. Ainda em 2017 iniciou seu trabalho como Professora Substituta de Língua Portuguesa e Língua Inglesa no Instituto Federal Sul-rio-grandense, Câmpus Jaguarão, onde atuou por dois semestres. Após, ingressou como professora de Inglês no Programa Bilíngue da Escola Mario Quintana e atualmente é Coordenadora do Programa Bilíngue nesta escola e Doutoranda em Letras na UFPel. Seu interesse de pesquisa é Metodologias Ativas de ensino, ensino e aprendizagem de Línguas, ensino de Inglês para Crianças, bem como tudo o que envolve formação e desenvolvimento de professores. E-mail: kieling.helena@gmail.com ORCID: https://orcid.org/0000-0001-8899-8247.
} 


\title{
ACTIVE METHODOLOGIES AND DIGITAL RESOURCES FOR L2 TEACHING: A REVIEW IN WAYS AND POSSIBILITIES
}

\begin{abstract}
This paper is a review article on Active Methodologies and Blended Learning for the teaching of L2 integrated with digital technologies, more specifically, how Active Methodologies present theoretical references for two gaps that are frequently presented on language teacher education: L2 teaching to children and the integrated employment of digital resources. The first gap consists of the lack of a specific approach for teaching L2 to children, in such a way that its pedagogical practice is a tinkering with elements of other subjects. The second one emphasizes the use of digital resources in an integrated way in learning spaces. We present a brief review of the main concepts of Active Methodologies. This article points out the necessity that this theme be present in pre-service teacher education, as well as a thoughtful integration of digital resources in pedagogical practices.

Keywords: Active Methodologies; L2 Teaching for children; Digital Resources; Teacher Training
\end{abstract}




\section{Introdução}

Não há formação inicial que contemple a variedade de contextos com os quais o futuro professor de línguas possa vir a se deparar na sua vida profissional. Porém, compreendendo um currículo como um "componente formador da realidade do sistema de educação no qual vivemos" (BROSSI et al., 2020, p. 99), entendemos que este deve buscar lançar um olhar sobre a educação contemporânea. Nesse sentido, no âmbito da formação de professores nas licenciaturas em Letras apontamos que olhar para a educação contemporânea requer atenção a duas questões: o ensino de uma Segunda Língua (L2) para crianças e a utilização de recursos digitais de forma integrada e significativa nas práticas de ensino de L2.

Neste sentido, apontamos que oferta do ensino de Língua Inglesa para Crianças (LIC) nos anos iniciais do Ensino Fundamental cresceu significativamente (RUBBO, 2016; TONELLI; CHAGURI, 2013) e despertou interesse da sociedade como um todo, incluindo instituições públicas e privadas, mesmo que a obrigatoriedade da Língua Inglesa (doravante LI) seja a partir do sexto ano (BRASIL, 2018). Para ilustrar, vemos uma profusão de escolas adotando e/ou montando programas bilíngues integrais ou parciais e, ao mesmo tempo, um certo impasse na seleção de profissionais habilitados para lecionar línguas para a pré-escola e os primeiros anos do Ensino Fundamental. Historicamente, tais níveis educacionais vêm contando com egressos de Pedagogia como professores, os quais, muitas vezes, não possuem proficiência em língua estrangeira adequada à função. Ou, também de forma problemática, estabelecimentos de ensino contratam egressos de licenciaturas em Letras, com proficiência, mas sem o preparo pedagógico prévio adequado para lecionar para crianças. Não consideraremos aqui, ainda que sabidamente existente, a contratação de pessoas com proficiência em língua estrangeira, mas sem formação pedagógica alguma - em Pedagogia ou Letras - justificada por uma tolerância não científica que concede a menor qualidade pois "os alunos são apenas crianças".

Para além da questão da formação e da atuação, a pandemia do Coronavírus (COVID-19), propagada por todo o planeta no primeiro semestre de 2020, levou as sociedades a tomarem medidas de isolamento ou distanciamento social, trazendo impactos diversos nas práticas sociais, com o fechamento de estabelecimentos e com ações restritivas à circulação em massa de pessoas. Dentre as práticas sociais atingidas, por óbvio estão as educacionais e, dentre os estabelecimentos, consequentemente as instituições de ensino, uma vez que representam historicamente ações e locais de alta aglomeração de pessoas.

Assim, a utilização de recursos digitais passou a fazer parte da rotina dos professores, o que evidenciou grande dificuldade e falta de preparação para tal cenário. De acordo com pesquisa do Instituto Península (INSTITUTO PENÍNSULA, 2020) $83 \%$ dos professores brasileiros não se sentem preparados para o ensino remoto e $88 \%$ revelam ter dado a primeira aula virtual após a pandemia, destacando como pauta a discussão sobre o quanto a utilização de recursos digitais devem estar presentes na formação docente a fim de dar 
suporte às práticas pedagógicas futuras e tendências educacionais embasadas nas habilidades do século XXI.

Nesse contexto mencionado destacamos o grande apelo à utilização das Metodologias Ativas (STAKER; HORN, 2015; BACICH et al., 2015; MATTAR, 2017; BACICH; MORAN, 2018; KIELING, 2017) com propostas pedagógicas em todas as áreas de ensino, pensando em novos formatos para a educação e escolas, alterando papéis de professores e de alunos. O trabalho com Metodologias Ativas busca que os professores elaborem novas estratégias pedagógicas, em comparação ao passado, em que a escola se restringia à memorização, o professor era o único detentor da informação e o papel do aluno era basicamente memorização de dados. Agora, mais do que nunca, com maior acesso à (des)informação por parte de todos, acreditamos que não seja mais possível que a educação seja baseada meramente em administração de conteúdos, sendo necessário ir além e desenvolver, cada vez mais, raciocínio crítico, análise e interpretação de dados, cidadania digital e, para tanto, mais do que acesso à informação, as práticas precisam ser pensadas de forma a colocar a atividade do aluno no centro do processo. E essa ressignificação, a nosso ver, deve começar desde os anos iniciais do Ensino Fundamental, com um ensino de L2 mediado, também, por recursos digitais desde a infância.

Uma premissa do trabalho com Metodologias Ativas é o papel central do aluno, ou seja, seu papel ativo no próprio processo de aprendizagem, o aprender fazendo. Em experiências em salas de aula presenciais ou híbridas o contexto de aprendizagem mediado por tecnologias digitais aparece como propício para práticas pedagógicas centradas no estudante. Sendo assim, uma das maneiras de formar professores preparados para lidar com os desafios da educação para o século XXI é que a nossa prática, enquanto formadores, sirva de exemplo. Porém, "para inovar, é preciso inovar-se. Se não houver um esforço pessoal para inovar a nós mesmos, não teremos condições de inovar a educação" (FUNDAÇÃO TELEFÔNICA, 2016, p. 13).

Neste artigo, apresentamos uma revisão das possibilidades apresentadas pelas Metodologias Ativas (STAKER; HORN, 2015; BACICH et al., 2015; MATTAR, 2017; BACICH; MORAN, 2018) como forma de fornecer ferramentas teóricas para abordar as lacunas da formação para ensino de línguas para crianças e do uso de tecnologias digitais para ensino híbrido. Nossa proposta é que se trabalhe no âmbito das Metodologias Ativas nas aulas de L2 desde os anos iniciais do Ensino Fundamental, pois o trabalho com elas propicia, em nossa ótica, a partir de seus modelos, o uso integrado de recursos digitais de forma mais significativa.

Para tanto, nossas seções estão organizadas em: (a) A lacuna na formação docente no ensino de L2 para Crianças; (b) Metodologias Ativas e as possibilidades de uso integrado de recursos digitais e (c) Considerações finais.

\section{A Lacuna na Formação Docente no Ensino de L2 para Crianças}

São amplamente conhecidas, dentro e fora do meio acadêmico, as motivações e os ganhos da aprendizagem de línguas, em especial, no caso do 
contexto de atuação dos autores do artigo, da LI. Uma das motivações está na relevância da LI como língua da globalização, pois as distâncias têm sido diminuídas, bem como as fronteiras diluídas, possibilitando uma interligação intensa e imediata da vida econômica e cultural de pessoas de todo o mundo com a comunicação desempenhando um papel fundamental neste processo (KUMARAVADIVELU, 2006, p. 131). A aprendizagem de línguas também surge como ganho para o indivíduo, com base em Rocha (2012), pela "importância do conhecimento de ao menos uma Língua Estrangeira (LE) como recurso de ação social" e, nesse sentido o inglês se destaca como o meio de comunicação planetária, tendo conquistado o status de língua franca, considerado um dos bens simbólicos mais valorizados na atualidade.

Defendemos, ainda, com base em Colombo e Consolo (2016), a ideia de que aprender uma L2 no início da vida não significa dar início ao processo de preparação para vida adulta, mas garantir espaço social, permitir (con)viver, atuar e interagir em um mundo como parte integrante dele enquanto criança, além disso, a aprendizagem de uma L2 na infância também permite uma formação mais integral no que tange ao conhecimento e respeito a outras culturas e sociedades, bem como benefícios cognitivos conforme têm apontado estudos relacionados à aprendizagem de uma L2 na infância (DAVID, 2017).

Podemos dizer com base em Rocha (2006) que a oferta de L2 para crianças no Brasil ainda configura uma colcha de retalhos, de forma que sua prática pedagógica é uma bricolagem com elementos de outras disciplinas e do ensino voltado a outras faixas etárias, portanto, com falhas aos interesses do públicoalvo. Colombo e Consolo (2016) ressaltam a necessidade de profundo debate sobre sua implementação para sair do chamado "ensino clandestino" (SANTOS, 2009) para um ensino refletido tanto em termos de metodologias quanto de políticas educacionais.

Nossa realidade revela grande demanda por professores de inglês que atuem no ensino para crianças, seja em escolas de idiomas, escolas particulares ou na demanda crescente de escolas bilíngues (Português-Inglês); no entanto, não há formação específica que contemple essa necessidade. De um lado temos o curso de Pedagogia, que prepara professores para atuação na educação infantil e que não contempla o ensino de L2 e, de outro, os cursos de Letras, em que a ênfase está na formação de docentes para atuar a partir dos anos finais do Ensino Fundamental, ou seja, pouco ou nenhum embasamento pedagógico para o ensino de crianças menores de 12 anos (CHAGURI; TONELLI, 2013).

Outro elemento importante para reflexão é que, nos cursos de Letras, somos preparados para dar aulas de língua inglesa e, ainda que se planeje a aula em termos comunicativos, existe a visão de que é uma aula de inglês, ou seja, o objetivo maior é a aprendizagem da língua através de tarefas que priorizem o desenvolvimento linguístico.

Para crianças, é comum a prática de ensino escolar de L2 resumir-se ao ensino de vocabulário (KAWACHI-FURLAN; LACERDA, 2020). Porém, é necessário pensar didaticamente uma aula através do inglês, ou seja, as estratégias 
pedagógicas nesse contexto infantil devem ter como propósito a mediação através $d a$ LI e não a aprendizagem formal do idioma. Brincar, cantar, utilizar materiais de papelaria, pintura e desenho, ou seja, as rotinas que já são familiares aos Anos Iniciais mediadas pela LI de forma lúdica.

Note-se, entretanto, não se tratar de uma tradução da aula regular dos Anos Iniciais para o inglês, se fosse assim tão simples não seria necessário desenvolver pesquisas sobre isso. A questão é: de que forma um professor pode fazer com que suas práticas através da LI encontrem ressonância interna com as crianças? Como fazer as atividades propostas serem significativas a ponto de a criança começar a construir o seu repertório linguístico também na L2?

Uma das formas de ressignificarmos a aula através do inglês para crianças é pensarmos em uma educação baseada na ideia de experiência conforme Dewey (2015). Fundamentalmente as crianças precisam experienciar para aprender. Em nossa perspectiva, o trabalho no âmbito das Metodologias Ativas pode contribuir com essa lacuna, a começar pela sua característica principal de privilegiar a ação do aluno no próprio processo de aprendizagem. Assim, a seguir, iremos apresentar uma revisão bibliográfica sobre as possibilidades apresentadas pelas Metodologias Ativas.

\section{Metodologias Ativas e as Possibilidades de Uso Integrado de Recursos Digitais}

Metodologias Ativas não são algo completamente novo. Essa concepção de ensino e aprendizagem surgiu muito antes das tecnologias digitais que modificaram nossa sociedade, com o movimento chamado Escola Nova, cujos pensadores como John Dewey (2015) e Édouard Claparède ${ }^{1}$ já defendiam uma metodologia de ensino centrada na aprendizagem pela experiência e no desenvolvimento da autonomia do aprendiz, algo que foi perdido em função da massificação da educação no formato mais tradicional de ensino.

Moran (2018) pontua que aprendemos quando alguém mais experiente nos fala e também a partir de um envolvimento mais direto, por questionamento e experiências. Contudo, o autor afirma que as metodologias predominantes de ensino são as dedutivas em que o professor transmite primeiro a teoria e depois o aluno a aplica em situações específicas. A partir disso, Moran constata que a aprendizagem por meio da transmissão é importante, mas aquela por questionamento e experimentação é mais relevante para uma compreensão mais ampla e profunda.

Segundo o autor, de certa forma, toda aprendizagem é ativa em alguma medida, porque demanda do estudante e do docente formas diferentes de movimentação interna e externa, de motivação, seleção, interpretação, etc. Acrescenta, ainda, que "o importante é estimular a criatividade de cada um e a percepção de que todos podem evoluir como pesquisadores, descobridores, realizadores, que conseguem assumir riscos, aprender com os colegas, descobrir seus potenciais." (MORAN, 2018 , p. 3). Sendo assim, o papel do professor também muda e ganha maior relevância. Este torna-se orientador ou mentor, explorando as affordances (em 
português, propiciamentos) apresentadas pelos alunos como sinais que ganham relevância para interações e ações mais significativas resultantes de atividades com propósito emocional e cognitivo envolvendo estímulos trazidos do meio (VAN LIER, 2004), pois deve ajudar os alunos a irem além de onde conseguiriam ir sozinhos. Estudos apontados por Moran (2018) revelam que quando o professor fala menos, orienta mais e o aluno participa de forma ativa, a aprendizagem é mais significativa. Moran destaca ainda que a combinação equilibrada da flexibilidade da aprendizagem híbrida com Metodologias Ativas (fazendo, refletindo, avaliando e compartilhando) facilita a ampliação de nossa percepção e competência em todos os níveis e reforça que as sociedades mais dinâmicas são as que incentivam a colaboração, o empreendedorismo e a criatividade.

Moran (2015) afirma que as instituições atentas às mudanças escolhem dois caminhos para implementação de novas pedagogias; o primeiro, mais brando, partindo de alterações progressivas em que se mantém o modelo curricular predominante e se adotam Metodologias Ativas como o Ensino Híbrido e a Aprendizagem Baseada em Projetos e, um segundo, mais amplo, com mudanças mais profundas adotando modelos disruptivos. Acreditamos que o melhor caminho é sempre o de um esforço institucional, com professores, coordenações e direção envolvidos em um processo brando e gradual de implementação do Ensino Híbrido, pois este propicia um uso reflexivo, integrado e significativo de recursos digitais no processo pedagógico. Corroboramos com o autor quando parte do pressuposto de que, métodos tradicionais de ensino, baseados na transmissão de conhecimentos, faziam mais sentido quando o acesso à informação era mais difícil, já que atualmente há a integração do mundo físico e digital. Ainda, Moran (2015) chama a atenção à reorganização do espaço físico, com salas de aula que privilegiem tanto aprendizagens individuais, quanto em grupos, além de conexão sem fio para o uso de tecnologias móveis. Segundo ele, algumas dimensões estão ficando claras na educação formal:

a. modelo Híbrido - em que nos reunimos de várias formas, física e virtual, de acordo com a necessidade e com flexibilidade;

b. Metodologias Ativas - porque aprendemos melhor através da prática e;

c. o modelo online com uma mistura de colaboração e personalização em que cada aluno desenvolve um percurso individual e participa em determinados momentos de atividades em grupo. O teórico enfatiza estarmos sendo pressionados para mudar, sem tempo para testar e que não vivemos mais em tempos sólidos, em que os conhecimentos adquiridos serviam de suporte a toda uma vida.

Em meio a isso, estamos em um cenário de insatisfação coletiva em que estudantes reclamam das aulas rotineiras, enfadonhas e pouco dinâmicas e os professores, da frustração pela pouca participação, desinteresse e desvalorização 
por parte dos estudantes em relação às aulas e às estratégias criadas para chamar a atenção deles. Inclusive agora, no contexto de ensino remoto devido à COVID-19, os professores queixam-se da pouca interação dos alunos que permanecem com as câmeras fechadas durante as aulas. Assim, percebe-se que a simples utilização de tecnologias digitais nas aulas não altera esse panorama, atestando que, estas por si só não transpõem velhos paradigmas.

A ação proposta para ensinar não pode ser desconectada daqueles que dela participarão, enfatizando a necessidade de que os docentes busquem novas metodologias de ensino que foquem no protagonismo dos alunos. É nesta perspectiva que se situam as Metodologias Ativas, deslocando a perspectiva do ensino (professor), para a aprendizagem (aluno) (DIESEL et al., 2017).

Enquanto que as metodologias mais tradicionais eram baseadas na transmissão de informações e no papel central do docente, as Metodologias Ativas buscam a construção e colaboração junto aos estudantes, estimulam a reflexão, a autonomia e a pesquisa. Sendo assim, os autores Diesel et al. (2017) apontam os princípios das Metodologias Ativas de ensino:

a. Aluno: centro do processo de aprendizagem - a partir de uma maior integração dele no processo de construção do próprio conhecimento e de uma participação mais efetiva em sala de aula.

b. Autonomia - a partir da postura mais ativa do estudante acredita-se estar estimulando o desenvolvimento de uma postura mais autônoma e crítica.

c. Problematização da realidade e reflexão - a partir da busca pela integração dos conteúdos com o contexto social.

d. Trabalho em equipe - a partir das atividades propostas que visam favorecer a interação constante entre os alunos.

e. Inovação - a partir da crença de que tais metodologias exigem ousadia e coragem dos professores.

f. Professor: mediador - a partir da constatação de que este assume uma postura investigativa da própria prática e da concepção de que a prática pedagógica é essencialmente formadora.

Como podemos perceber, as Metodologias Ativas não estão propondo algo totalmente novo e tem aproximações com correntes teóricas já conhecidas, como o construtivismo. Além da reflexão sobre o que é aprender e o que é ensinar, algo que as Metodologias Ativas apresentam como contribuição na área de ensino de L2 e que enxergamos como fundamental em toda ação pedagógica, especialmente com crianças, são os modelos de aplicação que propiciam a utilização de recursos digitais de forma integrada e significativa, conforme veremos a seguir. 


\section{As Possibilidades para Transform(ação) das Práticas Docentes} Através das Metodologias Ativas

Com base em Bacich et al. (2015) podemos dizer que as modificações possibilitadas pelas tecnologias digitais requerem novas metodologias de ensino, as quais necessitam de novos suportes pedagógicos, transformando o papel do professor e dos estudantes e ressignificando o conceito de ensino e aprendizagem. O ambiente físico das salas de aula não se modificou significativamente, talvez tenhamos uma lousa digital, alguns computadores e celulares, mas os alunos continuam sentados em suas classes com um professor à frente. Porém, é a interação gerada por essas tecnologias que pode (re)criar e ampliar o espaço da sala de aula para além da formatação tradicional e dos próprios limites escolares. "As tecnologias digitais modificam o ambiente, transformando e criando novas relações entre os envolvidos no processo de aprendizagem: professor, estudantes e conteúdos" (BACICH et al., 2015, p.50).

Começaremos nossa retomada sobre as possibilidades apresentadas pelas Metodologias Ativas pelo Ensino Híbrido que é uma excelente oportunidade de ressignificação do ambiente da sala de aula, pois ao inserir a tecnologia, "preserva os contornos brutos de uma sala de aula tradicional" e pode ser uma inovação sustentada da sala de aula, pois concilia o melhor dos dois mundos: presencial e online (STAKER; HORN, 2015, p.71). Essas ações devem ser incentivadas desde os Anos Iniciais do Ensino Fundamental a fim de que a longa trajetória de vida escolar contribua com o desenvolvimento de cidadãos mais autônomos.

\section{Aprendizagem Híbrida (Blended Learning)}

Nesta seção discutiremos as definições de Aprendizagem Híbrida e o motivo pelo qual este modelo vem se tornando tão relevante nas discussões sobre ensinoaprendizagem. Para tanto, a definição que tomamos como base é a de Horn e Staker (2015, p. 34-35):

[...] é um programa de educação formal no qual o aluno aprende, pelo menos em parte, online, com algum elemento de controle do aluno sobre o tempo, lugar e/ ou ritmo e, pelo menos em parte, em um local físico, supervisionado; é, sobretudo, uma experiência de aprendizagem integrada que propõe unir o antigo com o novo: presencial e online. (HORN; STAKER, 2015, p. 34-35)

Para o professor Mattar (2017) a Aprendizagem Híbrida já é sinônimo de educação semipresencial e pode ter dois sentidos, um (a) mais estrito e outro (b) mais amplo, conforme veremos a seguir com base em Mattar (2017, p. 27-29):

a. Sentido Estrito: Aprendizagem Híbrida seria a mistura entre a educação presencial e a distância (online). Teríamos em um extremo a educação presencial e, no outro, a distância e no centro a educação semipresencial. 
Neste sentido a Aprendizagem Híbrida já vem aparecendo como tendência em sucessivas versões do Horizon Reports e é este o sentido que dão Horn e Staker (2015) que apresentam quatro modelos conforme veremos adiante.

b. Sentido Amplo: de acordo com Mattar (2017) é o mais defendido pelo professor Moran e aponta para a combinação de diferentes espaços de aprendizagem ou entre aprendizagem formal e informal, ou seja, o online não seria um elemento essencial para a definição. Nesse sentido, se a Aprendizagem Híbrida pode não ser considerada uma metodologia ativa, certamente está associada ao seu uso, pois estaria ligado a aprendizagem mais centrada no aluno.

Em nossa concepção tanto o sentido mais estrito quanto o mais amplo são exemplos de Aprendizagem Híbrida e podem ser considerados como Metodologias Ativas, pois o cerne de ambas propostas está na ação do aluno e na proposição de novas estratégias de ensino. Principalmente porque defendemos que a ausência de recursos tecnológicos em determinado contexto educacional não seja motivo para não aplicação de novas estratégias de ensino.

A Aprendizagem Híbrida tem quatro modelos de acordo com a definição de Staker e Horn (2015): (1) Modelo de rotação, (2) Modelo flex, (3) Modelo à la carte e (4) Modelo Virtual Enriquecido, conforme podemos visualizar abaixo:

Figura 1: Modelos de Aprendizagem Híbrida

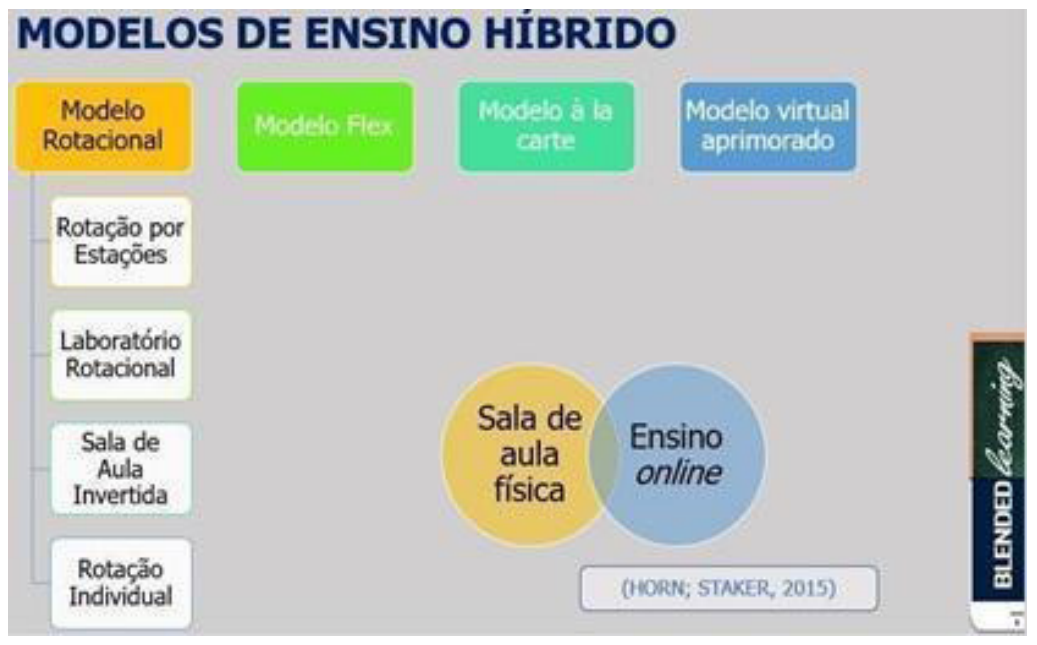

Fonte: Kieling (2017), adaptado de Horn e Staker (2015).

\section{Rotação por Estações}

O modelo de Rotação por Estações organiza os estudantes em grupos de modo que cada um realiza uma tarefa, de acordo com os objetivos do professor para a aula em questão. Após um determinado tempo, previamente combinado com os estudantes, eles trocam de grupo, e esse revezamento continua até todos terem passado por todos os grupos. 


\section{Laboratório Rotacional}

No Laboratório Rotacional, os estudantes usam o espaço da sala de aula e laboratórios. O modelo começa com a sala de aula tradicional e, em seguida, adiciona uma alternância para computador ou laboratório de ensino.

\section{Sala de Aula Invertida}

No modelo da Sala de Aula Invertida a teoria é estudada em casa, no formato online, e o espaço da sala de aula é utilizado para discussões, resolução de problemas, entre outras atividades. Esse modelo é também valorizado como a porta de entrada para o Blended Learning. Tais modelos apresentados até agora são considerados de inovação sustentada para a sala de aula, pois conciliam o melhor do ensino tradicional com o online. Mesmo assim, é indispensável que haja uma transformação na atuação do professor e do aluno para que esse novo espaço seja significativo.

Conforme Mattar (2017) afirma, é importante registrar que não é uma ideia nova, pois em cursos de pós-graduação já é comum que as aulas acabem envolvendo apresentações dos alunos e discussões, embora consideremos que muitas vezes os professores compreendam esse formato de forma errônea e renunciam de seu papel deixando tudo a cargo do aluno.

Essa inversão teria se tornado possível pelo desenvolvimento das tecnologias, pois as aulas em vídeo são consideradas o ingrediente chave na abordagem invertida, sendo criados e elaborados pelo professor ou selecionados de um repositório online. É importante ressaltar que a sala de aula invertida demanda bastante trabalho, pelo menos inicialmente, por parte do professor. Assim como é importante deixar claro o que se espera dos alunos antes, durante e depois das aulas. Mattar (2017) chama a atenção para o quanto são distintas as exigências para com os alunos comparado ao ensino tradicional. Além disso, os instrumentos de avaliação devem ser variados e em momentos distintos para que o professor possa ir sempre tendo esse feedback e acompanhamento dos alunos.

Essa organização é imprescindível para que o aluno não pense que não está tendo aula ou que apenas assiste a vídeos. É essencial que o aluno entenda que nesse modelo ele vai abandonar o seu papel passivo de receptor de informações.

Ainda no modelo de Rotação temos o primeiro exemplo de modelo disruptivo, ou seja, que rompe com a sala de aula tradicional conforme conhecemos:

\section{Rotação Individual}

Cada aluno tem um cronograma próprio e não alterna obrigatoriamente entre cada Estação.

Os modelos seguintes também são disruptivos e sugerem a aprendizagem online como eixo condutor do processo de ensino: 


\section{Modelo Flex}

O curso ou disciplina online é a espinha dorsal da aprendizagem, mesmo que direcione o aluno para atividades presenciais. Cada estudante tem um cronograma fluido e personalizado entre as modalidades de aprendizagem. $\mathrm{O}$ professor é presencial e ele ou outro adulto oferece apoio sempre que preciso em uma base presencial, flexível e adaptativa sempre que necessário.

\section{Modelo À la carte}

O nome vem da característica desta modalidade em que o aluno pode escolher um curso entre inúmeras opções para fazer um curso totalmente online que acompanha outras experiências na escola regular com professor online.

\section{Modelo Virtual Enriquecido}

Os estudantes têm sessões presenciais obrigatórias com professor presencial e complementam o trabalho de forma online quando estão fora da escola.

Em todos os modelos de Aprendizagem Híbrida o aluno é incentivado a ser mais autônomo e exercer seu protagonismo, ser mais responsável pela própria construção de conhecimento. No entanto, se quisermos alunos com mais iniciativa, precisamos dar início a esse processo desde a infância e transformar nossa atuação enquanto educadores e, para isso Bacich et al. (2015) chamam a atenção para o professor como designer de caminhos, utilizando a tecnologia como integradora de espaços. Para tanto, é necessário que, a partir de um plano de implementação, o professor defina qual o melhor modelo para sua realidade.

A seguir, veremos o modelo de Instrução por Pares (Peer Instruction) que é considerado um tipo de Sala de Aula Invertida, mas como tem suas características próprias, merece ser tratado separadamente.

\section{Peer Instruction (Instrução em Pares)}

A Peer Instruction pode ser considerada um tipo de sala de aula invertida, mas, por desenvolver uma sistemática própria, merece ser tratada separadamente. Eric Mazur (2015) seu criador, diz inclusive ter sido ela a origem da Sala de Aula Invertida. Ele observou que seus alunos estavam resolvendo problemas propostos pelo material didático, mas não estavam conseguindo resolver problemas do mundo real. Em outra situação, após tentativas de explicação, percebeu o quanto a discussão em pares acerca de um problema mais difícil tornou-se uma estratégia bem-sucedida. A partir de então, Mazur desenvolveu uma rotina em que os alunos participariam ativamente de seu processo de aprendizagem, dando origem à metodologia da Instrução por pares, a qual segue, resumidamente, a sequência abaixo apresentada por Mattar (2017, p. 41-48): 
1. Leituras/ vídeos online antes da aula

2. Questões online antes da aula

3. Breve explicação conceitual sobre o tema

4. Teste conceitual

5. Peer Instruction

6. Respostas individuais ao teste conceitual

7. Fechamento do professor

8. Questões online (MATTAR, 2017, p. 41-48).

1. Leituras/vídeos online antes da aula: os alunos leem o material didático e as anotações do professor antes das aulas;

2. Questões online antes da aula: Para garantir a leitura, são propostas três questões abertas que devem ser respondidas pela internet antes da aula. As duas primeiras são relacionadas a aspectos complexos da leitura e a última é sempre: "O que achou difícil ou confuso na leitura? Se nada foi difícil ou confuso, conte-nos o que achou mais interessante. Seja o mais específico possível". O acesso a essas respostas permite uma preparação na aula com mais foco nos alunos;

3. Breve explicação conceitual sobre o tema: já na aula, o professor faz uma exposição rápida sobre o assunto, entre 7 a 10 minutos. As dúvidas podem ser respondidas na aula ou em FAQ;

4. Teste conceitual: é proposto um teste conceitual de, no máximo, 2 minutos e o mesmo tempo é dado aos alunos para refletirem, primeiro individualmente, depois registram suas respostas, silenciosamente. $\mathrm{O}$ autor sugere que os últimos dez segundos sejam animados, com uma música, por exemplo, para gerar uma expectativa. Os testes podem ser de múltipla escolha, perguntas abertas, etc. e os alunos podem utilizar recursos diversos para responder, para depois serem expostas à turma e o professor fornecer um feedback imediato;

5. Desse teste, espera-se acertos entre $35 \%$ e $70 \%$, pois se menos de $35 \%$ acertarem, poucos alunos entenderam os conceitos e, se mais de $70 \%$ acertarem, a discussão posterior pode ser improdutiva. A partir desses dados, a aula pode tomar diferentes rumos:

6. o professor pode repetir a explicação se o percentual de acertos for baixo;

7. Com um nível razoável de acertos, formam-se grupos para discussão dos conceitos;

8. Com mais de $70 \%$ de acertos, o professor pode dar uma breve explicação sobre o tema e seguir adiante; 
9. No tempo total, os testes podem ocupar até metade da aula

10. Peer Instruction: nesse caso, o tema é retomado e os alunos conversam entre si a fim de convencer um ao outro que sua resposta está correta. O professor circula pela sala e esse momento leva em torno de 2 a 4 minutos;

11. Respostas individuais ao teste conceitual: Por fim, repetem o teste conceitual. Sempre há um aumento das respostas corretas;

12. Fechamento do professor: O professor brevemente, cerca de dois minutos, comenta a resposta correta e passa a um novo tópico;

13. Questões online: incluem soluções de problemas praticados em aula, individualmente e por escrito.

Conforme pode se ver, as etapas da instrução por pares, assim como os outros modelos de Metodologias Ativas, requerem elaboração de avaliações por parte do professor. Além disso, o professor deve valorizar todos os momentos de participação dos alunos: respostas ao questionário antes da aula, esforço e participação e respostas individuais.

\section{Aprendizagem Baseada em Projetos (ABP) - Project Based Learning $(P B L)$}

O principal objetivo da PBL é fazer com que o aprendizado dentro da escola tenha conexões com a vida real, o que tornaria o processo de aprendizagem muito mais significativo. Tavares e Potter (2018) chamam a atenção para a diferença entre os chamados projetos para finalizar uma unidade de trabalho, como um encerramento de um capítulo e do trabalho com PBL que envolve um processo mais complexo. E, neste sentido, a palavra processo tem uma relevância e deve ser enfatizada, conforme as autoras

Projetos são tarefas complexas, baseadas em questões e problemas desafiadores que envolvem os estudantes em solução de problemas, tomada de decisões ou atividades investigativas, além de dar a oportunidade de os alunos trabalharem com relativa autonomia por períodos de tempo e culminam em produtos reais ou apresentações. (TAVARES; POTTER, 2018, p. 11).

Ainda de acordo com as referidas autoras, o objetivo final do PBLé que os alunos realizem e apresentem um produto ou uma solução que possa fazer a diferença, seja informando sobre problemas da vida real, seja conscientizando as pessoas sobre isso, ou seja, apresentando uma relação de significado com a vida real.

Outros elementos importantes no trabalho com PBL são o desenvolvimento da colaboração e cooperação. Além de os alunos aprenderem a trabalhar 
colaborativamente, também aprendem a respeitar as opiniões dos outros, ouvir e comprometer-se e exercer o protagonismo, habilidades que serão importantes ao longo de suas vidas. Eles deverão desenvolver seu próprio questionamento sobre o tópico proposto, buscar informações e decidir sobre o produto final.

Em contrapartida, o papel do professor é de facilitador e orientador nessa trajetória, além de propor atividades interativas e avaliar o processo constantemente, não apenas o produto final. Além disso, propor a avaliação entre pares também é usual em PBL. Uma sugestão das autoras para isso é o compartilhamento dos critérios de avaliação com os estudantes.

Em resumo, as autoras abordam cinco pontos centrais no PBL:

1. Aprendizagem para a vida real;

2. Questões desafiadoras;

3. Processo;

4. Trabalho colaborativo;

5. Avaliação de pares, de processo e de produto;

Essas características tornam a PBL uma possibilidade bastante viável de ressignificar a prática de ensino de L2 para crianças, fugindo da prática voltada somente ao ensino de vocabulário, bem como oportunizando o uso integrado de recursos digitais de forma acompanhada pelo professor. Nesse sentido, os professores poderiam trazer uma temática específica e trabalhar a partir dela com viés voltado para a vida dos alunos, levando em consideração seu entorno, suas necessidades reais e a utilização da L2 na e para a infância.

Buscou-se, nesta seção, apresentar as possibilidades das Metodologias Ativas e de uma utilização integrada das mesmas às tecnologias digitais a partir de seus modelos como subsídio teórico à formação docente, considerando, principalmente, as lacunas mencionadas na introdução deste texto.

\section{Considerações Finais}

A Pandemia da Covid-19 alterou muitas práticas sociais e, dentre elas, as práticas pedagógicas das instituições de ensino que tiveram de ser adaptadas ao ensino remoto. Enquanto pesquisadores na área da Linguística Aplicada julgamos imprescindível a necessidade de atualização constante das práticas pedagógicas a fim de estabelecer, também, um diálogo constante com a sociedade.

Sendo assim, colocamos a questão da lacuna de formação de professores de línguas para o trabalho com crianças, haja vista a demanda crescente de profissionais que atuem nesse contexto. Ou seja, entendemos que é algo que não pode mais ser ignorado pelas instituições de Ensino Superior responsáveis pela 
formação inicial desses profissionais. Outrossim, ressaltamos que a formação teórica já presente nos cursos de Letras que aborda, por exemplo, métodos e abordagens de ensino de L2, não é suficiente para dar conta desse recorte. A baixa incidência de componentes teóricos e metodológicos voltados a esta especificidade nos currículos de grande parte das licenciaturas em Letras traz como resultado, em última análise, a impossibilidade e a dificuldade de egressos de tais cursos atuarem no ensino de línguas para crianças. Tal fato produz, como assinalamos, uma potencial carência na formação em línguas desses alunos.

Aliado a isso, a pandemia da COVID-19 evidenciou a falta de preparo adequado para o ensino com tecnologias digitais. Ainda que seja mais recorrente nos currículos, a reflexão sobre as tecnologias digitais e seu papel dentro da área de estudos da linguagem ainda nos parece insuficiente, como ficou evidente pelos entraves para a adoção de práticas pedagógicas remotas no ensino superior em decorrência da pandemia da COVID-19. Vemos, ao nosso redor, uma profusão de práticas sociais obrigatórias com tecnologias digitais - práticas as quais, invariavelmente, ocorrem por meio da linguagem: compras, transações bancárias, comunicações, reuniões de trabalho, dentre outras. Assim, fica ainda mais evidente, em um processo educacional que pretende preparar o indivíduo para o mundo, a necessidade de abordar de maneira consistente e ampliada o uso de tecnologias digitais na aprendizagem - aqui, de línguas. Digamos, por fim, que tal formação não surge como relevante apenas em um contexto pandêmico que obriga os indivíduos ao distanciamento, mas, ao contrário, contempla uma realidade de grande parte da sociedade, possibilitando, inclusive, oportunidades pessoais e profissionais relevantes.

Considerando as lacunas constatadas que motivaram a presente revisão, este artigo buscou fornecer subsídios teóricos à formação para este campo, através das possibilidades apresentadas pelas Metodologias Ativas para professores em formação, especialmente tendo em vista a atuação em contexto digital. Entendemos que a revisão bibliográfica sobre as possibilidades auferidas pelas Metodologias Ativas podem contribuir para estudos futuros investigando a prática do professor de línguas com grupos de crianças e as implicações e resultados de uma proposta baseada em Metodologias Ativas tanto em modelo presencial quanto em contexto híbrido.

Nota

1. A referência a Claparède e sua primeira menção ao protagonismo do aluno em uma publicação de 1931 se dá a partir do trabalho organizado por Hameline, Petraglia e Dias (2015).

\section{Referências}

BACICH, L.; NETO, A. T.; TREVISANI, F. de M. (Orgs.). Ensino Híbrido: Personalização e tecnologia na educação. Porto Alegre: Penso, 2015.

BACICH, L.; MORAN, J. (Orgs.) Metodologias ativas para uma educação inovadora: uma abordagem teórico-prática. Porto Alegre: Penso, 2018. 
BERGMANN, J.; SAMS, A. Sala de aula invertida: uma metodologia ativa de aprendizagem. Rio de Janeiro: LTC, 2019.

BRASIL. Ministério da Educação. Base Nacional Comum Curricular. Brasília, 2018.

BROSSI, G. C.; FURIO, M.; TONELLI, J. R. A. Currículo e Formação de professores de inglês em duas universidades: questões e desdobramentos. Reflexão e Ação. Santa Cruz do Sul, v. 28, n. 3, p. 96-112, set./dez. 2020.

CHAGURI, J. de P.; TONELLI, J. R. A. Existe uma política de ensino-aprendizagem de língua estrangeira para crianças. Ensino de língua estrangeira para crianças: o ensino e a formação em foco, v. 2, p. 37-58, 2013.

COLOMBO, C. S.; CONSOLO, D. A. O ensino de Inglês como Língua Estrangeira para Crianças no Brasil: cenários e reflexões. São Paulo: Cultura acadêmica, 2016.

DAVID, R. S. Professor quanto mais cedo é melhor? o papel diferencial da educação bilíngue. Revista X, Curitiba , v. 12 , n. 3 , p. 178-193. 2017.

DEWEY, J. Experience \& Education. New York: Free Press, 2015.

DIESEL, A.; BALDEZ, A. L. S.; MARTINS, S. N. Os princípios das metodologias ativas de ensino: uma abordagem teórica. Thema, Pelotas, v. 14, n. 1, p. 268-288, dez. 2017.

FUNDAÇÃO TELEFÔNICA. Inovaeduca - Práticas para quem quer inovar na educação. 2016.

HAMEline, D.; PETRAGLIA, I., DIAS, E. T. D. (Orgs.). Édouard Claparède. Coleção Educadores. Recife: Fundação Joaquim Nabuco, Editora Massangana, 2010. $148 \mathrm{p}$.

HORN, M. B.; STAKER, H. Blended: usando a inovação disruptiva para aprimorar a educação. Porto Alegre: Penso, 2015.

IP. Instituto Península. Pesquisa: sentimento e percepção dos professores brasileiros nos diferentes estágios do Coronavírus no Brasil. São Paulo, 2020.

KAWACHI-FURLAN, C. J.; LACERDA, V. V. Formação inicial de professores de inglês: educação linguística, tecnologias e práticas (des)contextualizadas. Revista (Con)Textos linguísticos, v. 16, n.29, p. 543-564. 2020.

KIELING, $\mathrm{H}$. dos S. Blended learning no ensino de inglês como Língua Estrangeira: um estudo de caso com professoras em formação. 2017. $84 \mathrm{f}$. Dissertação (Mestrado em Letras) - Programa de Pós-graduação em Letras. Pelotas: Universidade Católica de Pelotas. 2017.

KUMARAVADIVELU, B. A linguística aplicada na era da globalização. In: LOPES, L. P. da M. (Org.). Por uma linguística aplicada indisciplinar. São Paulo: Parábola Editorial, 2006. p. 129-148.

MATTAR, J. Metodologias Ativas: para a educação presencial, blended e a distância. São Paulo: Artesanato Educacional, 2017.

MAZUR, E. Peer Instruction: a revolução da aprendizagem ativa. Trad. Anatólio Laschuk. Porto Alegre: Penso, 2015.

MORAN, J. Metodologias ativas para uma aprendizagem mais profunda. In: BACICH, L.; MORAN, J. (Orgs.) Metodologias ativas para uma educação inovadora: uma abordagem teórico-prática [recurso eletrônico]. Porto Alegre: Penso, 2017. p. 2-25.

MORAN, J. Mudando a educação com metodologias ativas. Coleção Mídias Contemporâneas. Convergências Midiáticas, Educação e Cidadania: aproximações 
jovens. Vol. II. Carlos Alberto de Souza e Ofelia Elisa Torres Morales (Orgs.). PG: Foca Foto-PROEX/UEPG, 2015. p. 15-33.)

RAJAGOPALAN, K. O professor de línguas e a suma importância do seu entrosamento na política linguística de seu país. In: CORREA, D. A. (Org.). Política linguística e ensino de línguas. Campinas-SP: Pontes Editores, 2014. p. 73-82.

ROCHA, C. H. Provisões para ensinar LE no ensino fundamental de $1^{\text {a }}$ a $4^{\text {a }}$ séries: dos parâmetros oficiais e objetivos dos agentes. 2006. 340 f. Dissertação (Mestrado em Linguística Aplicada) - Instituto de Estudos da Linguagem, Universidade Estadual de Campinas, Campinas-SP. 2006.

RUBBO, G. F. S. Línguas estrangeiras nos primeiros anos do Ensino Fundamental: histórico, perspectivas e práticas. Reunião Científica Regional da ANPED: Educação, movimentos sociais e políticas governamentais. 24-27, jul. 2016. Disponível em < http://www.anpedsul2016.ufpr.br/portal/wp-content/ uploads/2015/11/eixo10_GABRIELLA-FRALETTI-DE-SOUZA-RUBBO.pdf > .

TAVARES, J. F.;POTTER, L. E. Project-based learning applied to the language classroom. Câmara Brasileira do Livro, São Paulo, 2018.

VAN LIER, L. The ecology and semiotics of language learning: a sociocultural perspective. Monterey: Kluwer Academic Publishers, 2004.

Recebido em: 13/04/2021

Aceito em: 17/05/2021 